\title{
ISOLASI DAN SELEKSI KHAMIR AMILOLITIK ASAL BUAH NANGKA (Artocarpus heterophyllus Lam.)
}

\author{
Isolation And Screening Amylolytic Yeast from Jackfruit (Artocarpus heterophyllus Lam.) \\ Tria Putri Wulandari ${ }^{1)}$, Dalia Sukmawati ${ }^{1 * *}$, Tri Handayani Kurniati ${ }^{1)}$ \\ 1) Program Studi Biologi FMIPA Universitas Negeri Jakarta, Jl. Rawamangun Muka, RT.11/RW.14, \\ Rawamangun, Jakarta Timur, Daerah Khusus Ibukota Jakarta 13220 \\ *Corresponding Email: Sukmawatidalia@gmail.com
}

\begin{abstract}
The aim of this research is to find the isolates of yeast that have the ability to produce enzyme amylase. The strains that can produce the amylase enzyme are characterized by a clear zone around colonies after addition of iodine solution in medium containing $1 \%$ starch soluble. Activity of amylase enzyme can be determined by measuring using spectrophotometer at $\lambda 540 \mathrm{~nm}$. The isolation result obtained 75 representative yeast isolates with colony color white butyrous $16 \%$, white mucoid $29.3 \%$, yellowish white $18.7 \%$, cream $20 \%$, peach mucoid $9.3 \%$, and orange mucoid $6,7 \%$. Screening results showed that 8 isolates were able to produce an amylase enzyme with code isolates $\mathrm{K} 33$, $\mathrm{K} 34, \mathrm{~K} 36, \mathrm{~K} 37, \mathrm{~K} 48, \mathrm{~K} 107$, and $\mathrm{K} 128$. A total of two potential yeast isolates in yielding amylase with $\mathrm{K} 34$ and $\mathrm{K} 39$ isolate codes had amylolytic index 2.89 and 2.27 . The highest enzyme activity was produced by K48 $(0.88 \mathrm{U} / \mathrm{mL})$.
\end{abstract}

keywords:

\section{PENDAHULUAN}

Peranan enzim sebagai biokatalisator dalam berbagai bidang industri semakin penting. Salah satu enzim yang berperan adalah enzim amilase. Konsumsi enzim amilase di dalam negeri mencapai 2500 ton dengan nilai impor 187,5 Milyar di tahun 2015 (KEMENDAG, 2015). Amilase merupakan enzim yang dapat digunakan untuk menghidrolisis polisakarida seperti pati menjadi gula sederhana (Yalçın \& Çorbacı, 2013). Enzim amilase umum digunakan dalam industri pembuatan roti, tekstil, deterjen serta industri farmasi (Pandey et al., 2000; Souza \& Magalhães, 2010).

Enzim amilase dapat dihasilkan oleh mikroorganisme (Abu et al., 2005). Mikroorganisme yang menjadi sumber utama enzim amilase antara lain: khamir (Ramasamy et al., 2011). Khamir dapat ditemukan dari berbagai macam substrat seperti di daun (Sukmawati et al. 2015; Sukmawati, 2017). Selain itu khamir juga dapat ditemukan di subtrat buah. Tan gana et al. (2014) berhasil melakukan isolasi khamir dari buah pisang dan diperoleh amiloitik antara 
lain: Brandoniozyma complexa, Pichia anomala, Pseudozyma prolifica, Hypopichia burtoni Candida wangnamkhiaoensis, Kodamaea ohmeri dan Debaryomyces nepalensis. Selain itu, Oliveira et al. (2015) melaporkan telah dilakukan isolasi khamir dari buah-buahan dan diperoleh beberapa khamir amilolitik antara lain: Candida parapsilosis, C. glabrata, dan Rhodotorula mucilaginosa.

De Becze (2000) menyatakan bahwa khamir dapat ditemukan di tempat yang kaya akan kandungan gula misalnya pada buah. Menurut Tejpal \& Amrita (2016) cempedak merupakan buah yang mempunyai kandungan gula sekitar 60\%. Buah cempedak masih satu marga dengan buah nangka. Sehingga diduga kandungan gula buah nangka sama dengan buah cempedak. Kandungan gula yang relatif tinggi pada buah nangka dapat dijadikan substrat khamir untuk tumbuh. Diduga pada buah nangka terdapat khamir yang mampu menghasilkan enzim amilase.

\section{METODOLOGI PENELITIAN}

\section{ISOLASI KHAMIR}

Khamir yang digunakan dalam penelitian diisolasi dari 2 buah nangka yang berasal dari Kota Bekasi. Bagian buah nangka yang diisolasi adalah daging buah dan biji. Isolasi khamir dilakukan menggunakan medium Yeast Malt Agar (YMA) mengandung (g/L); 3 g yeast extract, $3 \mathrm{~g}$ malt extract, $5 \mathrm{~g}$ pepton, $10 \mathrm{~g}$ glukosa dan $15 \mathrm{~g}$ agar. Metode isolasi khamir menggunakan spread plate dan teknik dilusi dengan dua kali pengulangan.

\section{SELEKSI KHAMIR BERDASARKAN ZONA BENING}

Seleksi khamir amilolitik dilakukan menggunakan metode difusi agar dengan uji hidrolisis amilum. Suspensi khamir umur 48 jam diinokulasikan kedalam medium yeast pepton starch agar (YPSA) dengan komposisi $(\mathrm{g} / \mathrm{L})$ : $10 \mathrm{~g}$ soluble starch; $5 \mathrm{~g}$ pepton; $2 \mathrm{~g}$ ekstrak khamir; 0,1 $\mathrm{g} \mathrm{MgSO}_{4} .7 \mathrm{H}_{2} \mathrm{O} ; 0,1 \mathrm{~g} \mathrm{CaCl}_{2} .7 \mathrm{H}_{2} \mathrm{O} ; 0,5 \mathrm{~g} \mathrm{KH}_{2} \mathrm{PO} 4,20 \mathrm{~g}$ agar. Inkubasi dilakukan pada suhu $30^{\circ} \mathrm{C}$ selama 72 jam. Hidrolisis amilum ditandai dengan adanya zona bening yang terbentuk di sekitar koloni setelah penambahan reagen iodin. Isolat khamir amilolitik diujikan kemampuannya berdasarkan indeks amilolitik berdasarkan rumus Goldbeck et al. (2012):

$$
I A=\frac{\text { Diameter zona bening }}{\text { Diameter koloni }}
$$

\section{MEDIUM FERMENTASI ENZIM AMILASE}

Medium fermentasi dibuat dengan komposisi (g/L): $30 \mathrm{~g}$ yeast extract; $20 \mathrm{~g}$ pepton; $10 \mathrm{~g}$ soluble starch; $2 \mathrm{~g}$ $\mathrm{CaCl}_{2} ; 0,5 \mathrm{~g} \mathrm{MgSO}_{4} ; 0,1 \mathrm{FeSO}_{4}$. Perbandingan inokulum dengan media adalah 1:50 (v/v). Inkubasi dilakukan pada suhu kamar $\pm 28^{\circ} \mathrm{C}$ selama 48 jam pada rotary shaker kecepatan $150 \mathrm{rpm}$ (Yalçın \& Çorbac1, 2013).

\section{PENGUJIAN AKTIVITAS ENZIM AMILASE}

Kultur cair khamir disentrifugasi dengan kecepatan 10.000 rpm selama 15 menit. Supernatan yang mengandung ekstrak kasar dari enzim amilase diambil untuk diuji aktivitasnya (Oliveira et al., 2015). Sebanyak 0,5 $\mathrm{ml}$ larutan ekstrak enzim kasar ditambahkan kedalam $0,5 \mathrm{ml}$ substrat pati $1 \%$ terlarut dengan 0,05 M larutan bufer fosfat, kemudian diinkubasikan pada suhu $60^{\circ} \mathrm{C}$ selama 10 menit. Campuran ditambahkan $1 \mathrm{~mL}$ reagen asam 3,5dinitrosalisilat (DNS) dan reaksi dihentikan dengan pemanasan pada suhu $100^{\circ} \mathrm{C}$ selama 5 menit. Satu unit aktivitas amilase adalah banyaknya enzim yang dapat menghasilkan gula reduksi sebanyak $1 \mu \mathrm{mol}$ per menit per ml larutan enzim pada kondisi pengujian yang dilakukan. Campuran lalu diukur absorbansinya menggunakan spektrofotometer 
pada panjang gelombang $540 \mathrm{~nm}$ dan dikonversikan menggunakan larutan standar maltosa. Pengujian dilakukan dengan 4 kali ulangan.

Tabel 1. Perolehan isolat khamir hasil isolasi dari buah nangka (Artocarpus heterophyllus Lam.) pada medium YMA, inkubasi suhu $\pm 28^{\circ} \mathrm{C}$ selama 48 jam

\begin{tabular}{lllll}
\hline \multirow{2}{*}{ Sampel } & \multicolumn{4}{c}{ Jumlah koloni khamir pada plot } \\
\cline { 2 - 5 } & 1 & 2 & 3 & \\
\hline Biji/seed & 59 & 54 & 21 & $134(41,23 \%)$ \\
Buah/ pulp & 103 & 49 & 39 & $191(58,77 \%)$ \\
Total & & & & $325(100 \%)$ \\
\hline
\end{tabular}

\section{HASIL DAN PEMBAHASAN}

\section{ISOLASI KHAMIR}

Hasil isolasi diperoleh sebanyak 325 isolat khamir yang terdiri dari 134 isolat khamir dari biji (41,23\%) dan 191 isolat khamir dari buah (58,77\%) (Tabel 1). Berdasarkan jumlah isolat keseluruhan yang diperoleh menunjukkan bahwa jumlah isolat khamir pada buah lebih banyak dibandingkan pada biji.

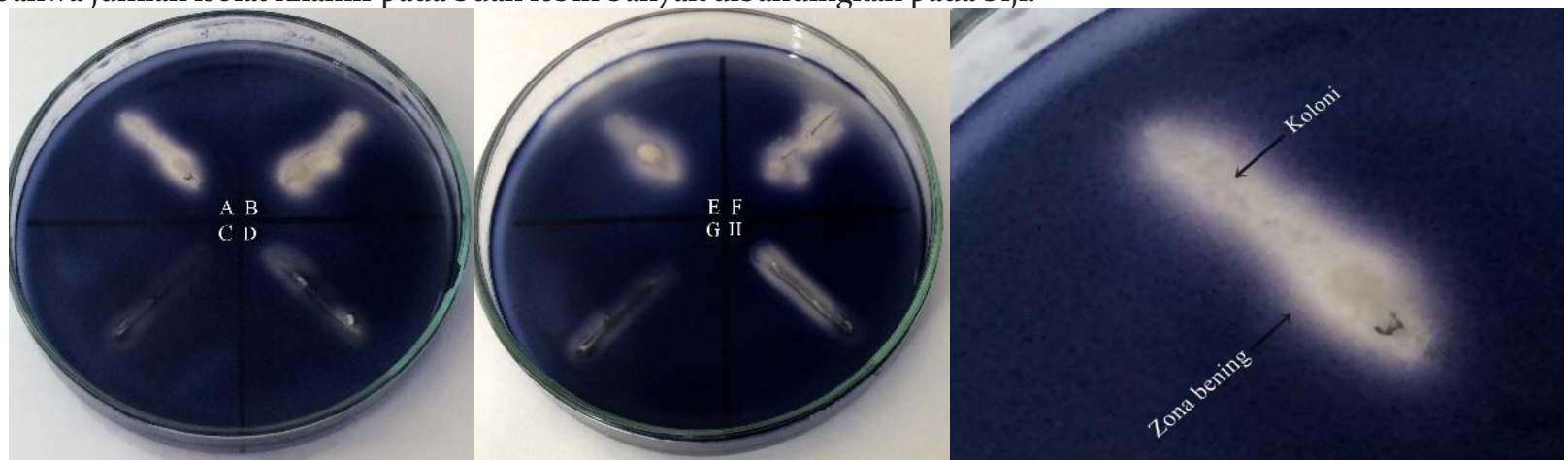

Gambar 1. Zona bening yang terbentuk di sekitar koloni khamir pada medium YPSA, inkubasi suhu $30^{\circ} \mathrm{C}$ selama 72 jam. Isolat khamir amilolitik (A) K34, (B) K39, (E) K48, (F) K107 dan isolat non-amilolitik (C) K23, (D) K28, (G) K100, (H) K105

Hal ini kemungkinan karena kandungan nutrien seperti gula, vitamin serta makro dan mikronutrien lebih banyak terkandung di buah dibandingkan di biji. Hal ini sesuai dengan penelitian Swami et al. (2012) yang menyebutkan kandungan nutrien buah nangka di buah lebih melimpah dibandingkan di biji. Tejpal \& Amrita, (2016) mengemukakan bahwa buah nangka memiliki nutrien yang lebih kaya daripada di biji.

\section{SELEKSI KHAMIR BERDASARKAN ZONA BENING}

Seleksi khamir amilolitik dilakukan pada 75 isolat representatif berdasarkan morfologi secara makroskopik. Hasil skrining produksi enzim amilase terhadap 75 isolat khamir diperoleh 8 isolat yang potensial menghasilkan enzim amilase dan 67 isolat tidak menghasilkan zona bening. Hal tersebut ditandai dengan adanya zona bening di sekitar koloni isolat khamir (Gambar 1). Zona bening yang terbentuk di sekitar koloni khamir menunjukkan bahwa isolat tersebut mampu menghidrolisis pati. Pati akan membentuk kompleks berwarna biru pekat dengan reagen iodin. Reaksi iodin-pati disebabkan oleh adanya heliks amilosa dan iodin dalam membentuk $\mathrm{I}^{3-}$ yang mengisi inti heliks. Hidrolisis pati secara aktif oleh enzim amilase akan menyebabkan kompleks pati-iodin terurai sehingga 
membentuk zona bening.

Tidak terbentuknya zona bening di sekitar koloni menandakan adanya reaksi antara reagen iodin dan pati yang tidak terhidrolisis di dalam medium YPSA (Cappucino \& Sherman, 2002). Penelitian Tan Gana et al. (2014), melaporkan bahwa adanya kemampuan atau daya menghasilkan enzim amilase suatu mikroba ditandai dengan terbentuknya zona bening dalam medium yang mengandung pati.

Delapan isolat khamir yang memiliki kemampuan menghasilkan enzim amilase diuji kemampuannya berdasarkan indeks amilolitik. Berdasarkan indeks amilolitik (Tabel 2) diperoleh nilai IA yang bervariasi. Sebanyak 2 isolat khamir yang potensial dalam menghasilkan amilase dibanding dengan 6 isolat lainnya, yaitu isolat K34 dan K39 dengan nilai IA sebesar 2,89 dan 2,27. Sedangkan isolat K33 memiliki nilai IA terendah, yaitu 1,04. Hal ini sesuai dengan penelitian Bansal et al. (2011) melakukan skrining terhadap fungi yang mampu menghasilkan amilase dengan IA sebesar 2,95. Ouédraogo et al. (2012) yang berhasil mengisolasi khamir dan melakukan skrining khamir potensial penghasil amilase dari kentang dengan nilai IA 2,35. Desai et al. (2012) berhasil mengisolasi khamir dan diperoleh nilai IA 2,60.

Tabel 2. Nilai indeks amilolitik (IA) isolat khamir asal buah nangka pada medium YPSA, inkubasi suhu $30^{\circ} \mathrm{C}$ selama 72 jam

\begin{tabular}{|l|l|}
\hline Kode isolat & Nilai IA $(\mathrm{mm})($ Mean \pm SE $)$ \\
\hline K33 & $1,04 \mathrm{a} \pm 0,04$ \\
\hline K34 & $2,89 \mathrm{~d} \pm 0,30$ \\
\hline K36 & $1,34 \mathrm{ab} \pm 0,06$ \\
\hline K37 & $1,25 \mathrm{a} \pm 0,23$ \\
\hline K39 & $2,27 \mathrm{c} \pm 0,19$ \\
\hline K48 & $1,95 \mathrm{c} \pm 0,06$ \\
\hline K107 & $1,84 \mathrm{bc} \pm 0,24$ \\
\hline K128 & $1,26 \mathrm{a} \pm 0,07$ \\
\hline
\end{tabular}

Tabel 3. Nilai aktivitas enzim amilase isolat khamir potensial amilase inkubasi suhu $\pm 28^{\circ} \mathrm{C}$ selama 48 jam

\begin{tabular}{|l|l|}
\hline Kode isolat & Nilai aktivitas amilase $(\mathrm{U} / \mathrm{mL})($ Mean \pm SE $)$ \\
\hline K33 & $0.62 \mathrm{~b} \pm 0.03$ \\
\hline K34 & $0.64 \mathrm{~b} \pm 0.04$ \\
\hline K36 & $0.40 \mathrm{a} \pm 0.02$ \\
\hline K37 & $0.44 \mathrm{a} \pm 0.00$ \\
\hline K39 & $0.59 \mathrm{~b} \pm 0.01$ \\
\hline K48 & $0.88 \mathrm{~d} \pm 0.01$ \\
\hline K107 & $0.74 \mathrm{c} \pm 0.05$ \\
\hline K128 & $0.47 \mathrm{a} \pm 0.02$ \\
\hline
\end{tabular}

Keterangan: Angka yang diikuti oleh huruf yang sama tidak berbeda nyata pada $\alpha=0,05$ uji Duncan

\section{UJI AKTIVITAS ENZIM AMILASE}

Pengujian aktivitas enzim amilase dilakukan untuk mengetahui aktivitas enzim amilase terhadap 8 isolat khamir potensial. Pengukuran aktivitas enzim amilase dilakukan menggunakan kultur khamir dalam bentuk suspensi. Suspensi khamir ditumbuhkan dalam medium YPSB (yeast pepton starch broth) dengan komposisi pepton, yeast extract, pati di dalamnya. Pepton dan yeast extract menjadi sumber nitrogen organik yang berfungsi sebagai makronutrien penting dalam pertumbuhan sel. Pati, selain sebagai makronutrien penting, berperan juga sebagai sumber karbon penginduksi enzim amilase (Gupta et al., 2003).

Berdasarkan pengukuran aktivitas enzim amilase (Tabel 3), isolat yang memiliki aktivitas enzim tertinggi adalah isolat $\mathrm{K} 48$ dengan aktivitas enzim sebesar 0,88 $\mathrm{U} / \mathrm{mL}$, sedangkan aktivitas enzim terendah pada isolat K33 yaitu sebesar 0,40 U/mL. Ouédraogo et al. (2012), berhasil mengukur aktivitas enzim amilase pada khamir potensial penghasil amilase hasil isolasi dari kentang sebesar 0,774 U/mL. Sedangkan Oliveira et al. (2015) berhasil mengukur aktivitas enzim amilase pada khamir Saccharomyces cerevisiae aktivitas enzimnya sebesar 0,34 U/ $\mathrm{mL}$. 


\section{KESIMPULAN}

Berdasarkan data hasil penelitian, dapat disimpulkan bahwa diperoleh 8 isolat khamir potensial penghasil enzim amilase yang diisolasi dari buah nangka (A. heterophyllus Lam.) dengan kode K33, K34, K36, K37, K39, K48, $\mathrm{K} 107$, dan K128. Isolat K48 memiliki aktivitas enzim amilase terbesar dibandingkan dengan isolat lainnya, yaitu sebesar $0,88 \mathrm{U} / \mathrm{mL}$

\section{DAFTAR PUSTAKA}

Abu EA, Ado SA, \& James DB. 2005. Raw starch degrading amylase production by mixed culture of Aspergillus niger and Saccharomyces cerevisae grown on Sorghum pomace. Afr. J. Biotechnol. (4): 785 - 790.

Bansal N, Tewari R, Gupta JK, Soni R, \& Soni SK. 2011. A novel strain of Aspergillus niger producing a cocktail of hydrolytic depolymerising enzymes for the production of second generation biofuels. Peer-Reviewed Article, 6, 552-569.

Cappuccino JG \& Sherman N. 2002. Microbiology: A laboratory manual, $9^{\text {th }}$ ed. Addison-Wilsey. California.

De Becze GI. 2000. A microbilogica process report yeasts: morphology. Research Laboratories. Schenley Distillers, Inc, Lawrenceburg, Indiana.

Desai MV, Dubey KV, Vakil BV, Ranade VV. 2012. Isolation, identification and screening of the yeast flora from indian cashew apple for sugar and ethanol tolerance. Int. J. Biotechnol. Well. Indus. 1: 259-265.

Goldbeck R, Andrade CCP, Pereira GAG, \& Filho FM. 2012. Screening and identification of cellulase producing yeast-like microorganisms from Brazilian biomes. Afr. J. Biotechnol. 11(53): 11595-11603.

Gupta R, Gigras P, Mohapatra H, Goswami VK, \& Chauhan B. 2003. Microbial $\alpha$-amylases: a biotechnological prospective. Process. Biochem. 38: 1599-1616.

Kementerian Perdagangan Republik Indonesia. 2015. Perkembangan ekspor impor komoditi Indonesia. http://www. kemendag.go.id. [18 Januari 2018].

Oliveira APA, De Silvestre MA, Alves-prado HF, Rodrigues A, Fossa M, Fonseca GG, \& Leite RSR. 2015. Bioprospecting of yeasts for amylase production in solid state fermentation and evaluation of the catalytic properties of enzymatic extracts. Afr. J. Biotechnol. 14(14): 1215-1223.

Ouédraogo N, Savadogo A, Zongo C, Somda K, \& Traoré A. 2014. High performance amylolytic yeast strains isolation and identification for valorization of potatoes waste available in Burkina Faso. Int. Food Res. J. 19(4): 1463-1469.

Pandey A, Nigam P, Soccol CR, Soccol VT, Singh D, Mohan R. 2000. Advances in microbial amylases. J. Biotech. App. Biochem. 133-152.

Ramasamy K, Zakaria ZA, \& Sufian AS. 2011. In vitro antimicrobial activity of Muntingia calabura. Afr. J. Microbiol. Res. 4 (4): 304-8.

Souza PM \& Magalhães PO. 2010. Application of microbial alpha-amylase in industry - a review. Braz. J. Microbiol. 41: 850-861.

Swami SB, Thakor NJ, Haldankar PM, \& Kalse SB. 2012. Jackfruit and its many functional components as related to human health : A Review. Comprehensive Reviews in Food Science and Food Safety, 11: 565-576. 
Sukmawati D, A Oetari, D Hendrayanti, M Atria dan Wellyzar S. 2015. Identfication of Phylloplane Yeast from Paper Mulberry (Broussonetia papyrifera L.) In Java, Indonesia. Malaysian Journal of Microbiology, 11(4): 324340.

Sukmawati D. 2016. Antagonism Mechanism of Fungal Contaminant on Animal Feed using Phylloplane Yeast Isolated from the Bintaro Plant (Cerbera manghas L.) Bekasi in Java, Indonesia. International Journal of Current Microbiology and Applied Sciences, 5(5): 63-74.

Tan Gana NHT, Mendoza BC, \& Monsalud RG. 2014. Isolation, screening, and characterization of yeasts with amyloytic, lipolytic, and proteolytic activities from the surface of philippine bananas (Musa spp.). Philipp. J. Sci. 143: 81-87.

Tejpal A \& Amrita P. 2016. Jackfruit: A health boon. Int. J. Res. Ayurveda. Pharm., 7(3) :59-64.

Yalçın HT \& Çorbacı C. 2013. Isolation and characterization of amylase producing yeasts and improvement of amylase production. Turk. J. Bioch. 38(2): 101-108. 